\title{
O terapeuta ocupacional no processo de ressocialização de adolescentes em conflito com a lei privados de liberdade: transformação através da ocupação*
}

\author{
The occupational therapist in the process of \\ re-socialization of youth offenders deprived of \\ freedom: transformation through occupation
}

\author{
Dayane Regina dos Santos ${ }^{1}$,Andréa Maria Fedeger ${ }^{2}$
}

\begin{abstract}
SANTOS, D. R. dos; FEDEGER, A. M. O terapeuta ocupacional no processo de ressocialização de adolescentes em conflito com a lei privados de liberdade: transformação através da ocupação. Rev. Ter. Ocup. Univ. São Paulo, v.19, n. 2, p. 100-107, maio/ago. 2008.

RESUMO: O presente trabalho apresenta, através de pesquisa bibliográfica realizada, uma reflexão acerca das contribuições do terapeuta ocupacional no processo de ressocialização de adolescentes em conflito com a lei institucionalizados. Apresentam-se considerações referentes à influência do contexto sócio-histórico na produção da criminalidade juvenil e às diretrizes atuais da legislação e políticas públicas de atenção ao adolescente infrator. Características e pressupostos da Terapia Ocupacional no campo social de atuação também são abordados. Verificou-se a escassez de publicações de terapeutas ocupacionais brasileiros acerca da temática e, portanto, a necessidade de pesquisa, considerando-se a sua relevância social, prática e teórica. A literatura consultada apresenta importantes contribuições do terapeuta ocupacional no contexto de privação de liberdade, destacando-se o potencial de transformação, expressão e humanização do ambiente institucional facultado pelas atividades.
\end{abstract}

DESCRITORES: Terapia ocupacional. Delinqüência juvenil/reabilitação. Adolescente institucionalizado. Vulnerabilidade social. Política social.

\footnotetext{
" Este artigo é um desdobramento do Trabalho de Conclusão de Curso "Contribuições do terapeuta ocupacional no processo de ressocialização de adolescentes em conflito com a lei privados de liberdade”, apresentado na Universidade Federal do Paraná - UFPR, em maio de 2008.

1 Acadêmica do $9^{\circ}$ período do curso de Terapia Ocupacional da UFPR.

2 Docente do Curso de Terapia Ocupacional da UFPR. Mestre em Psicologia da Infância e da Adolescência pela UFPR. Orientadora do trabalho.

Endereço para correspondência: Rua Gerd Claassen, 591. Butiatuvinha. CEP: 82400-220. Curitiba, PR. E-mail: day-regina@hotmail. com
} 


\section{INTRODUÇÃO}

adolescência é uma etapa peculiar do
desenvolvimento humano, durante a qual
ocorrem transformações definitivas e complexas, de caráter físico, cognitivo e psicossocial, além das alterações nos papéis sociais e ocupacionais. De acordo com Berger (2003), adolescentes que se desenvolvem em ambientes adversos e sem o apoio de figuras significativas, tendem a cometer sérios deslizes no caminho em direção à maturidade.

$\mathrm{O}$ envolvimento de adolescentes em atos infracionais violentos no Brasil aumentou significativamente nos últimos anos, em número e gravidade das ações, configurando-se como um grave problema social. Compreende-se violência neste trabalho, conforme a definição de Minayo (2002), como o uso da força para a exclusão, abuso ou aniquilamento do outro, sendo este um indivíduo, um grupo, um segmento social ou um país. No contexto brasileiro, a situação é delicada e gera diversas controvérsias com relação à legislação vigente, pautada nos preceitos do Estatuto da Criança e do Adolescente - ECA, que considera penalmente inimputáveis os menores de dezoito anos (BRASIL, 1990). A redução da maioridade penal é considerada por setores da sociedade como a única forma de reverter este quadro. No entanto, a transferência de adolescentes para presídios não parece ser a melhor solução, considerando-se os prejuízos sociais, físicos e psicológicos gerados por esse processo de institucionalização, em especial para indivíduos em condição peculiar de desenvolvimento.

O terapeuta ocupacional, adentrando a prática no campo social de atuação, tem sido convidado a integrar as equipes de atenção a adolescentes institucionalizados, deparando-se, muitas vezes, com situações desafiadoras, para as quais não se encontra preparado (GALHEIGO, 2003a).

Diante do exposto, propõe-se, neste artigo, apresentar as investigações realizadas, na pesquisa de publicações de autores brasileiros, acerca das contribuições do terapeuta ocupacional no processo de ressocialização de adolescentes em conflito com a lei privados de liberdade, estabelecendo um diálogo com os autores internacionais, Duncan (2004) e Wittman e Velde (2001), previamente consultados. Além disso, faz-se necessário apresentar, inicialmente, algumas considerações acerca da influência do contexto social na produção da criminalidade juvenil; do caráter atual da legislação e das políticas públicas de atenção e proteção ao adolescente em conflito com a lei, com especial atenção à medida de privação de liberdade; e dos pressupostos das ações da Terapia Ocupacional no campo social no Brasil, situando o adolescente em conflito com a lei como sujeito alvo dessa prática.

Estruturou-se o trabalho de acordo com a metodologia proposta por Gil (1999) para as pesquisas sociais, lançandose mão da pesquisa bibliográfica da literatura referente ao tema, publicada entre os anos 2000 e 2007. Buscouse publicações em bases de dados (LILACS, Bireme e SciELO), periódicos e livros. Além dos autores da Terapia Ocupacional consultados, recorreu-se a contribuições de alguns autores de outras áreas do conhecimento, especificamente Médico-biológicas, Pedagogia, Psicologia, Saúde Pública e Sociologia, além de documentos, leis e indicadores sociais e políticos. A pesquisa é de caráter explicativo, sendo que a preocupação central está em identificar os fatores que determinam ou contribuem para a ocorrência do fenômeno social em questão e suas implicações para a Terapia Ocupacional. As bases lógicas da investigação seguem o método dialético, considerandose que esse possibilita uma interpretação dinâmica e totalizante da realidade, tendo em vista que os fatos sociais não podem ser compreendidos isoladamente, apartados de suas influências políticas, econômicas e culturais.

Considerando o número reduzido de profissionais envolvidos nesta área de atuação e a escassez de publicações referentes ao assunto, ressalta-se a relevância social, prática e teórica da temática. Destaca-se, também, a necessidade de reflexão a cerca da construção de práticas que contribuam para a ressocialização e emancipação desses indivíduos, em condição peculiar do desenvolvimento humano, de forma que essa ocorra de maneira digna, satisfatória e humanizada.

\section{$O$ adolescente infrator: a influência do contexto sócio-histórico-político}

O contexto social exerce grande influência no comportamento dos indivíduos, uma vez que, conforme Bueno (2007), os processos de constituição das habilidades humanas estão associados e sofrem interferência das condições e trajetórias sociais do sujeito e sua família, estando enraizadas em suas histórias, nos processos socializadores, nos valores e afetos que as suportam, enfim, nas condições de existência de cada indivíduo.

Neste sentido, segundo Sanchez e Françoso (2007), apesar do aumento do número de adolescentes envolvidos em atos infracionais violentos, esses indivíduos continuam sendo mais vítimas do que autores da violência. De acordo com as autoras, os adolescentes apresentam vulnerabilidade a diversas situações de risco e violência, por estarem em um estágio peculiar de desenvolvimento. Esse quadro é agravado, como afirmam Moreira e Queiroz (2005) e Assis 
e Constantino (2005), quando se consideram contextos sócio-históricos, como o do Brasil, nos quais predominam desigualdades sociais intensas, geradoras de violência e de todas as formas de desrespeito aos direitos humanos, que encontram em crianças e adolescentes as suas maiores vítimas.

Com enfoque na criança e no adolescente, a violência constitui-se em todo ato ou omissão de pessoas e instituições capazes de causar danos físicos, sexuais e/ou psicológicos a estas vítimas. A violência pode ser qualificada, como violência estrutural, delinqüência e violência doméstica. A delinqüência ou violência infanto-juvenil deve ser analisada com maior cuidado, uma vez que está inserida em uma sociedade extremamente desigual, na qual as transgressões quase sempre envolvem crianças e adolescentes pobres, que perambulam ou trabalham nas ruas ou que são institucionalizados. Este tipo de violência deve, portanto, ser vista de maneira articulada à violência estrutural, ou seja, aquela que reflete nas condições de vida das crianças e adolescentes, devido a decisões históricoeconômicas e sociais, tornando vulnerável seu crescimento e desenvolvimento (MINAYO, 2002).

$\mathrm{O}$ desenvolvimento moral truncado é apontado por Assis (2002) como uma das conseqüências evidenciadas por jovens que vivem sob a égide da violência. Crianças e adolescentes que se desenvolvem em ambientes violentos, segundo a autora, deixam de adquirir valores éticos básicos, contribuindo para a não valorização da vida humana. Este fato somado à inexistência de projetos a longo prazo e perspectivas de vida futura, devido à convivência com a situação de perigo iminente, justifica as ações violentas, desde que essas resultem em ganhos financeiros ou prestígio social para o adolescente (ASSIS, 2002).

O modelo sócio-econômico instalado no país, gerador de intensas disparidades sociais, leva, de acordo com Moreira e Queiroz (2005), muitos jovens a escolherem o mundo da violência como principal referência identitária. Isso acontece, segundo as autoras, como resultado do processo de desenvolvimento desses indivíduos, que crescem enfrentando várias dificuldades, desde as carências no atendimento às necessidades básicas (alimentação, moradia, acesso à escola, à saúde, ao emprego), até o acesso aos bens da cultura e do lazer.

Quando o Estado deixa de assumir sua função de provedor de políticas sociais básicas de qualidade e garantidor da justiça social, torna as condições fundamentais de sobrevivência, desenvolvimento e emancipação pauperizadas ou inviabilizadas. Dessa maneira, a família torna-se o primeiro alvo da desagregação social, tendo sua função de provedora e cuidadora bastante prejudicada pela falta de recursos materiais e pelo despreparo e grau de tensão dos provedores, impedidos de exercer plenamente sua função de acolhimento, desenvolvimento e manutenção de seus membros. A escassez de recursos para a manutenção da vida e a insatisfação das necessidades, permanentemente criadas pela sociedade de consumo, contribuem para a construção do sujeito excluído. Assim, a violência assume lugar privilegiado no discurso, passando a ser uma das principais formas de comunicação e mediação das insatisfações e conflitos, sendo, também, uma das poucas oportunidades do exercício do poder e da autodeterminação dos que se sentem excluídos (GALHEIGO, 2003b).

O documento oficial, no qual são baseadas as políticas públicas de atenção e proteção a crianças e adolescentes no Brasil, é o Estatuto da Criança e do Adolescente - ECA, sancionado pela Lei $\mathrm{n}^{\circ} 8.069$, de 1990 , tendo origem a partir do artigo 227 da Constituição Federal (BRASIL, 1990). O ECA, segundo Galheigo (2003a), inaugurou um novo olhar para o tratamento às questões da infância e da adolescência, transformando a perspectiva assistencialista em uma prática fundada nos princípios do direito. Tratandose especificamente do adolescente autor de ato infracional, destaca-se, conforme Campos e Panúncio-Pinto (2005), que essa legislação garante ao mesmo a (re) educação através da aplicação de medidas sócio-educativas. Salienta-se que a educação difere-se da punição, por oferecer um ambiente propício para a assimilação de conhecimentos, enquanto punir constitui apenas o ato de aprisionar e excluir da sociedade.

A medida socioeducativa, de acordo com o Instituto de Ação Social do Paraná - IASP (GOVERNO DO ESTADO DO PARANÁ, 2006), é uma decisão judicial que tem por finalidade determinar a execução da ação socioeducativa fundamentada na doutrina de proteção integral. É destinada exclusivamente ao adolescente autor de ato infracional e visa a reintegração deste à sociedade, proporcionando-lhe oportunidades de desenvolver competências para ser e conviver sem entrar em conflito com a lei.

O Estatuto da Criança e do Adolescente (BRASIL, 1990) determina em seu artigo 112 as seguintes medidas, no caso da verificação da prática de ato infracional por adolescente: advertência, obrigação de reparar o dano, prestação de serviços à comunidade, liberdade assistida, inserção em regime de semiliberdade e internação em estabelecimento educacional. A internação, contexto foco deste estudo, constitui-se, de acordo com o artigo 121 do ECA (BRASIL, 1990), em medida socioeducativa privativa de liberdade, sujeita aos princípios de brevidade, excepcionalidade e respeito à condição peculiar de pessoa em desenvolvimento. A privação de liberdade é aplicada 
quando tratar-se de ato infracional cometido mediante grave ameaça ou violência à pessoa; no caso de reincidência no cometimento de outras infrações; ou por descumprimento reiterado e injustificável de medida socioeducativa anteriormente imposta (BRASIL, 1990).

Em 2006, a Secretaria Especial de Direitos Humanos e o Conselho Nacional de Direitos da Criança e do Adolescente apresentaram o Sistema Nacional de Atendimento Socioeducativo - SINASE. O SINASE reafirma a natureza pedagógica da medida socioeducativa prevista no ECA, e espera criar condições possíveis para que o adolescente em conflito com a lei deixe de ser compreendido como um problema e possa ser visto com uma prioridade social no Brasil (CONSELHO NACIONAL DOS DIREITOS DA CRIANÇA E DO ADOLESCENTE, 2006).

Entretanto, faz-se necessário considerar, conforme lembra Galheigo (2003a), que, embora tenha sido promulgado em 1990, o ECA encontra-se, ainda, em fase de implementação. Tal fato contribui, como aponta Almeida (2004), para que se observe, em algumas instituições, o descumprimento das diretrizes estabelecidas, configurandose em inoperância do sistema e fraqueza institucional. Conclui-se, dessa forma, tendo em vista a opinião de De Lavor (2007), que um futuro mais justo e saudável é possível, mesmo quando há desvios no caminho, basta que a lei que já existe seja cumprida.

\section{A Terapia Ocupacional no Campo Social}

A Terapia Ocupacional é uma profissão da área da saúde que, diante da ampliação do conceito de saúde - entendido como o completo estado de bem estar biopsicossocial, e não somente como a ausência de doença - estendeu seu campo de ação, abrangendo práticas sociais, através do uso de atividades, visando a promoção da saúde e a (re) inserção social de indivíduos excluídos por problemas físicos, mentais ou sociais de forma integral e independente (CAMPOS; PANÚNCIO-PINTO, 2005).

O terapeuta ocupacional, desta forma, como um agente social, deve buscar favorecer, de acordo com Galheigo (2003b), a organização do coletivo, a fim de possibilitar a construção da cidadania plena. Compreendendo a cidadania de acordo com a concepção de Moreira e Queiroz (2005), de que essa privilegia a perspectiva dos sujeitos, ultrapassando a noção jurídica dos direitos consagrados em lei, supondo, portanto, a intervenção dos indivíduos na definição de alvos pretendidos e na conquista do que consideram direitos.

Sendo assim, para Barros, Ghirardi e Lopes (2002), em uma sociedade marcada por diferenças sociais significativas, o terapeuta ocupacional pode atuar, contribuindo para o processo de transformação social em direção a uma maior equidade. Neste sentido, Malfitano (2005) acredita que para a atuação efetiva no campo social é preciso reconhecer o outro como interlocutor, participante ativo, do processo. A Terapia Ocupacional, para tanto, deve desenvolver projetos, através de uma intervenção calcada nos conceitos de autonomia, cidadania e direito, utilizando-se de intervenções individuais e coletivas, direcionadas a possibilitar o alcance dos desejos e necessidades do sujeito, bem como a ampliação de vivências e repertórios sócio-culturais para sua vida (MALFITANO, 2005).

A atenção do terapeuta ocupacional, no campo social, é direcionada, de acordo com Barros, Ghirardi e Lopes (2002) a grupos sociais em processos de ruptura das redes sociais de suporte. Entre estes grupos, estão indivíduos que sofrem processo de exclusão social, através de institucionalização, para sua recuperação, educação ou repressão - entre eles os adolescentes privados de liberdade.

Galheigo (2003b) afirma que a prática da Terapia Ocupacional social é voltada à população, cujas necessidades são conseqüências de suas condições de exclusão do acesso aos bens sociais e que têm sua problemática manifestada pelo agravamento das condições de vida a que está submetida. Considerando-se que o adolescente infracionou devido a sua condição de exclusão e que a privação de liberdade configura-se como agravamento em suas condições de vida, é possível situar o adolescente em conflito com a lei institucionalizado como sujeito alvo das ações da Terapia Ocupacional no campo social.

\section{A terapia ocupacional e o adolescente em conflito com a lei: transformação através da ocupação}

A partir da leitura de publicações das autoras internacionais Duncan (2004), Wittman e Velde (2001), referentes à atuação do terapeuta ocupacional em contextos privativos de liberdade, e considerando a realidade atual brasileira, que evidencia o despreparo para lidar com questões referentes à ressocialização de adolescentes em conflito a lei institucionalizados, julgou-se pertinente investigar, nas publicações de autores brasileiros, as possibilidades de ação do terapeuta ocupacional neste processo. A seguir apresenta-se o resultado da pesquisa bibliográfica, estabelecendo-se um diálogo entre os autores brasileiros e estrangeiros consultados, considerando suas importantes contribuições para a construção dessa prática.

A Terapia Ocupacional tem sua proposta de atuação junto 
à criança e ao adolescente em situação de vulnerabilidade, entre estes o adolescente em conflito com a lei privado de liberdade, no sentido de possibilitar que estes indivíduos sejam capazes de experimentar e ressignificar sua relação com o fazer, simultaneamente à possibilidade de (re) estabelecer laços sociais mais sólidos. Através da criação de espaços de acolhimento, busca-se desenvolver a capacidade de elaboração de conflitos, de formas alternativas à linguagem da violência. Deve-se, portanto, possibilitar ao adolescente a vivência da construção de projetos que resultem na aprendizagem da construção de um novo projeto de vida (BARROS et al. 2007b).

Duncan (2004) considera, com base em sua prática na África do Sul, que as ações do terapeuta ocupacional devem ser direcionadas para a desconstrução de discursos e identidades ocupacionais criminais, construídas ao longo do desenvolvimento do indivíduo, inserido, muitas vezes, em contextos sociais adversos, nos quais predominavam a criminalidade e a violência. Duncan (2004) acredita que a ocupação seria um "catalisador" para a reflexão moral e a aquisição de formas de ser e agir alternativas à violência.

Nesse sentido, Campos e Panúncio-Pinto (2005) afirmam que a atuação do terapeuta ocupacional parte do pressuposto de que a transformação de situações indesejadas, a construção de um projeto de vida e a promoção de resiliência para os adolescentes institucionalizados devem passar necessariamente pelo "fazer". As autoras consideram, tendo em vista o trabalho realizado no Centro de Atendimento e Reeducação do Menor Infrator (Minas Gerais), que a utilização da atividade como recurso terapêutico, instrumental da Terapia Ocupacional, pode contribuir para minimizar os efeitos adversos da institucionalização, além de auxiliar o adolescente a construir a ponte para o mundo exterior.

O ECA(BRASIL,1990) prevê em seu artigo 124 como direitos do adolescente privado de liberdade, entre outros, a realização de atividades educacionais, profissionalizantes, culturais, esportivas e de lazer. Em muitas instituições o jovem recebe o acompanhamento pedagógico e é obrigado a cumprir uma rotina diária de atividades, mantendo-se "ocupado" durante a maior parte do tempo. No entanto, de acordo com Duncan (2004), manter os adolescentes "ocupados" em um trabalho inútil e sem significado não colabora para o crescimento e transformação pessoal. $\mathrm{O}$ terapeuta ocupacional, segundo a autora, devido à sua compreensão da articulação entre saúde, ocupação e qualidade de vida, é o profissional qualificado para mapear as ocupações possíveis no ambiente institucional e desenvolver programas de reabilitação baseados na ocupação e voltados à reintegração social.
Almeida (2004) aponta, a partir de sua experiência em uma Unidade Educacional da FEBEM de Ribeirão Preto, que a contribuição da Terapia Ocupacional no contexto institucional é identificada na abordagem e no conceito de atividade utilizado. Para Almeida (2004), a atividade é compreendida como mediação da relação dos jovens entre si, com a instituição, com a equipe e com a comunidade, podendo, ainda, ser vista, como um meio para a busca de qualidade de vida. O terapeuta ocupacional poderá contribuir para a construção de espaços que se configurem como canais de expressão dos adolescentes, de maneira a fornecer-lhes alternativas de expressar suas angústias, diante do sofrimento gerado pelo processo de privação de liberdade e exclusão social. Deve-se possibilitar que o sujeito reflita sobre a maneira como ele está existindo no mundo, avaliando quais os meios para sua expressão subjetiva e para a criação de respostas às interferências de outros à sua trajetória. Assim, uma vez que o indivíduo percebe o espaço de intervenção como um espaço possível de (re) construir sua existência no mundo, ele passa a estar aberto para aprender novas estratégias de ação e expressão (ALMEIDA, 2004).

Duncan (2004) acredita que a atuação do terapeuta ocupacional, na atenção ao adolescente em conflito com a lei, deve ocorrer por meio da habilitação da ocupação, ao realizar programas que favoreçam o desenvolvimento de habilidades para a transformação pessoal e restituição de objetivos de vida através de atividades dirigidas. E, ainda, por meio da justiça ocupacional, sendo essa a compreensão das necessidades ocupacionais de indivíduos privados de liberdade como parte de uma sociedade justa e restitutiva (que favoreça o retorno à sociedade) e não meramente punitiva.

Duncan (2004) menciona o processo de justiça restaurativa que visa redirecionar os adolescentes do sistema de justiça criminal para um novo padrão de vida que previna a reincidência, assim como as medidas sócioeducativas, previstas no artigo 112 do ECA (BRASIL, 1990). No programa de justiça restaurativa, o terapeuta ocupacional pode auxiliar os adolescentes a escolher caminhos alternativos ao crime e à violência, facilitando o processo de substituição da identidade criminal por uma identidade ocupacional, favorecendo a compreensão da dinâmica de seu comportamento violento e apresentandolhes padrões comportamentais alternativos, através de ocupações significativas e com propósitos. Salientando-se que tais atividades configuram-se como o principal meio de exercitar responsabilidade, autonomia e escolhas em um ambiente, onde até mesmo o tipo e a quantidade da comida são determinados por outra pessoa (DUNCAN, 2004). 
Wittman e Velde (2001), com base em sua experiência em unidades prisionais nos Estados Unidos, acreditam que o principal objetivo da intervenção terapêutica ocupacional junto aos indivíduos privados de liberdade é ajudá-los na transição do ambiente prisional para a comunidade, auxiliando-os a alcançar habilidades necessárias para a vida comunitária, que são, muitas vezes, afetadas pelo sistema institucional. As autoras consideram, ainda, que tais ações contribuem para o aumento da qualidade de vida e, conseqüentemente, para mudanças comportamentais que reduzem a necessidade de segurança máxima, além do aumento da auto-estima e otimização do desempenho ocupacional dos desses indivíduos.

As ocupações oferecidas pela instituição devem ocorrer, conforme aponta Duncan (2004), em paralelo aos processos de reflexão e suporte para grupos, nos quais deve-se estabelecer uma relação entre as atividades e seus significados. A autora sugere, ainda, que os caminhos ocupacionais (passado, presente e futuro) individuais e coletivos devem ser analisados nas atividades em grupo, buscando a construção de uma identidade ocupacional alternativa.

Galheigo (2003a) afirma que por ser um profissional que se preocupa com o cotidiano e o fazer humano, o terapeuta ocupacional pode contribuir significativamente na melhoria da atenção oferecida a crianças e adolescentes abrigados. A autora considera que, em contextos institucionais, o profissional pode atuar buscando favorecer a organização de uma vida cotidiana mais saudável, na qual conflitos rotineiros possam ser mais adequadamente solucionados $\mathrm{e}$ a promoção de uma rotina institucional rica em experiências e flexível no funcionamento. Para tanto, Galheigo (2003a) sugere a realização de trabalhos grupais que favoreçam o fortalecimento de vínculos e facilitem a dinâmica operativa do cotidiano institucional e, também, atendimentos individuais que contribuam para a comunicação, expressão e elaboração de conflitos. Além disso, o terapeuta ocupacional pode, também, oferecer aos educadores sociais elementos que os auxiliem a lidar com as situações mais difíceis.

Com base nas possibilidades apresentadas, pode-se afirmar que a Terapia Ocupacional, através de ocupações bem direcionadas e com significado, pode contribuir para a melhoria da qualidade de vida dos adolescentes privados de liberdade, favorecendo-lhes a experiência da transformação pessoal e promovendo oportunidades de desenvolvimento. Possibilitando, dessa maneira, que estes sujeitos estejam preparados socialmente para a liberdade e contribuindo para a humanização do ambiente institucional, bem como para a satisfação de algumas das responsabilidades sociais da profissão.

\section{CONSIDERAÇÕES FINAIS}

A pesquisa bibliográfica apontou para um aumento das pesquisas referentes ao campo social de atuação da Terapia Ocupacional no Brasil, entre os anos 2000 e 2007 , encontrando-se autores que se dedicaram à atenção a crianças e adolescentes em situação de risco social. No entanto, verificou-se, no período de tempo determinado para este estudo, significativa escassez de publicações de terapeutas ocupacionais brasileiros acerca do trabalho com adolescentes privados de liberdade, apenas duas publicações referentes ao tema foram encontradas - Almeida (2004) e Campos e Panúncio-Pinto (2005). Destaca-se, portanto, a necessidade de pesquisa sobre essa temática, tendo em vista sua relevância social, prática e teórica.

Apesar de escassa, a literatura consultada apresenta importantes contribuições do terapeuta ocupacional no contexto de privação de liberdade, destacando-se o potencial de transformação, expressão e qualidade de vida facultados pelas atividades. Dessa forma, considera-se que o terapeuta ocupacional auxilia na construção de um ambiente institucional mais humanizado que possibilite que a emancipação e (re)inserção social do adolescente ocorram de forma digna e satisfatória. Vale ressaltar, ainda, o caráter interdisciplinar de uma ação efetiva, além da importância do trabalho em rede, considerando-se os equipamentos sociais e as políticas públicas desenvolvidas para a atenção à clientela abordada nesse estudo.

Este artigo apresenta aos terapeutas ocupacionais uma reflexão acerca da importância de suas contribuições para a elaboração e implementação de programas e políticas públicas que permitam a construção de direitos humanos e sociais, em consonância com os preceitos do Estatuto da Criança e do Adolescente, considerando-se a complexidade que envolve a temática de adolescentes em conflito com a lei. Destacando-se, ainda, a responsabilidade social da profissão, que deve estar comprometida com a sociedade na resolução de seus problemas, compreendendo o envolvimento de adolescentes em atos infracionais como um grave problema social.

Zelar pelos direitos das crianças e adolescentes, que são o futuro do nosso país, independentemente de sua situação, é dever de todo cidadão brasileiro. Em especial de profissionais, entre eles o terapeuta ocupacional, que adquirem, durante a sua formação, conhecimentos capazes de contribuir para a construção de uma sociedade mais justa e igualitária, que permita que indivíduos em condição peculiar do desenvolvimento cresçam entendendo e exercendo a verdadeira cidadania. 
SANTOS, D. R. dos, et al. O terapeuta ocupacional. Rev. Ter. Ocup. Univ. São Paulo, v. 19, n. 2, p. 100-107, maio/ago. 2008.

SANTOS, D. R. dos; FEDEGER, A. M. The occupational therapist in the process of re-socialization of youth offenders deprived of freedom: transformation through occupation. Rev. Ter. Ocup. Univ. São Paulo, v.19, n. 2, p. 100-107, maio/ago. 2008.

\begin{abstract}
This article is a result of bibliographic research. It proposes considerations about the occupational therapist's contributions to the re-socialization process of youth offenders law in a deprived of freedom. It presents considerations referring to the influence of socio-historic context on the production of youth criminality and to the present legislation and public politics regarding youth offenders. Occupational Therapy's characteristics and purposes in the social field are also approached. Even though there is a few brazilian occupational therapists publications about this topic, that suggest a needed for researches, the material reviewed brings consideration for social interventions through practical and theoretical relevance. The literature consulted shows important contributions from occupational therapists about this topic, highlighting the potential of expression, humanization and transformation through occupation.
\end{abstract}

KEY WORDS: Occupational therapy. Juvenile delinquency/rehabilitation. Adolescent, institutionalized. Social vulnerability. Public policy.

\title{
REFERÊNCIAS
}

ALMEIDA, M. M. O jornal e o vídeo como meio de expressão de jovens internados na unidade educacional da FEBEM de Ribeirão Preto. Rev. Ter. Ocup. Univ. São Paulo. São Paulo, v. 15, n. 1, p. 33-38. 2004.

ASSIS, S. G. Crescendo em meio à violência. In: WESTPHAL, M. F. (org.). Violência e criança. São Paulo: EDUSP, 2002. p. $115-124$.

ASSIS, S. G.; CONSTANTINO, P. Perspectivas de prevenção da infração juvenil masculina. Rev. Ciên. e Saúde Coletiva. Rio de Janeiro, v. 10, n. 1, 2005. Disponível em: <http://www.scielo.br/ scielo.php?pid $=$ S1413-81232005000100014\&script $=$ sci_arttext $>$ Acesso em 20 ago. 2007.

BARROS, D. D.; GHIRARDI, M. I. G.; LOPES, R. E. Terapia ocupacional social. Rev. Ter. Ocup. Univ. São Paulo. São Paulo, v. 13, n. 3, p. 95-103. 2002.

BARROS, D. D.; LOPES, R. E.; GALHEIGO, S. M. Novos espaços, novos sujeitos: a terapia ocupacional no trabalho territorial e comunitário. In: CAVALCANTI, A.; GALVÃO, C. Terapia ocupacional: fundamentação e prática. Rio de janeiro: Guanabara Koogan, 2007b. p. 354-363.

BERGER, K. S. Adolescência: o desenvolvimento biossocial. In:

. O desenvolvimento da pessoa: da infância à terceira idade. 5. ed. Rio de Janeiro: LTC, 2003.

BRASIL. Presidência da República. Secretaria Especial de Direitos Humanos. Lei Federal n. 8.069/90, 13/07/1990, dispõe sobre o Estatuto da Criança e do Adolescente.
BUENO, K. M. P. Os processos sociais de constituição das habilidades. Rev. Ter. Ocup. Univ. São Paulo. São Paulo, v. 18, n. 2, p. 47-53. 2007.

CAMPOS, F. R. S.; PANÚNCIO-PINTO, M. P. Compreendendo o significado da privação de liberdade para adolescentes institucionalizados. In: Simpósio Internacional do Adolescente. An. 1, 2005. Disponível em: <http://www.proceedings.scielo.br/ scielo.php?pid=MSC0000000082 $005000200014 \&$ script $=$ sci arttext> Acesso em 06 ago. 2007.

CONSELHO NACIONAL DOS DIREITOS DA CRIANÇA E DO ADOLESCENTE. Sistema Nacional de Atendimento Socioeducativo - SINASE. Brasília, 2006.

DE LAVOR, A. Em São Carlos, o Eestado cumpre a lei. Radis - comunicação em saúde, Rio de Janeiro, n. 57, p. 9-13, maio, 2007.

DUNCAN, M. Occupation in the criminal justice system. In: WATSON, R.; SWARTZ, L. Transformation through occupation: human occupation in context. London: Whurr Publisherers, 2004. p. 129-142.

GALHEIGO, S. M. O abrigo para crianças e adolescentes: considerações acerca do papel do terapeuta ocupacional. Rev. Ter. Ocup. Univ. São Paulo. São Paulo, v. 14, n. 2, p. 85-94. 2003a.

GALHEIGO, S. M. O social: idas e vindas de um campo de ação em terapia ocupacional. In: PÁDUA, E. M. M.; MAGALHÃES, L. V. (orgs). Terapia ocupacional: teoria e prática. São Paulo: Papirus, 2003b. p. 29-46. 
SANTOS, D. R. dos, et al. O terapeuta ocupacional. Rev. Ter. Ocup. Univ. São Paulo, v. 19, n. 2, p. 100-107, maio/ago. 2008.

GIL, A. C. Métodos e técnicas de pesquisa social. 5a. ed. São Paulo: Atlas, 1999.

GOVERNO DO ESTADO DO PARANÁ. Instituto de Ação Social do Paraná. Cadernos do IASP. Gestão de Centro de Socioeducação. Curitiba, 2006.

MALFITANO, A. P. S. Campos e núcleos de intervenção na terapia ocupacional social. Rev. Ter. Ocup. Univ. São Paulo, v. 16, n. 1, p. 1-8. 2005.

MINAYO, M. C. S. O Significado Social e para a saúde da violência contra crianças e adolescentes. In: WESTPHAL, M. F. (Org.). Violência e criança. São Paulo: EDUSP, 2002. p. 95-114.
MOREIRA, E. M.; QUEIROZ, T. C. N. Juventude e cultura em comunidades precarizadas: a difícil construção da cidadania. In: ALVIM, R.; QUEIROZ, T.; FERREIRA JÚNIOR, E. (orgs.). Jovens e juventude. João Pessoa: Editora Universitária - PPGS/ UFPB, 2005. p. 51-64.

SANCHEZ, R. N.; FRANÇOSO, L. A. O adolescente em situação de risco. In: LOPEZ, F. A.; CAMPOS JUNIOR, D. Tratado de pediatria. São Paulo: Manole, 2007. p. 417-425.

WITTMAN, P. P.; VELDE, P. B. Occupational therapy behind bars. OT Practice. The American Occupational Therapy Association, v. 6 , n. 19, p. 11-15. 2001. 